\title{
Finite Element Analysis of Guyed Masts under Seismic Excitation
}

\author{
Adlin Nelofer $\mathbf{J}^{1}$, N Saravana Kumar ${ }^{2}$ \\ ${ }^{1}$ PG Student, Department of Civil Engineering, Mepco Schlenk Engineering College, Sivakasi, India. \\ ${ }^{2}$ Assistant Professor Senior Grade, Department of Civil Engineering, Mepco Schlenk Engineering College, Sivakasi, India.
}

\begin{abstract}
The seismic response of guyed masts is analyzed using the Finite element program ABAQUS in terms of their structural behavior and input seismic accelerograms. Detailed numerical simulations of four masts with varied parameters involving guy cables equally spaced at different stay levels are modeled to explore the dynamic behavior of mast under harmonic seismic ground motion. Modal dynamic and steady state dynamic analysis are carried out to analyze the behavior of guyed mast during drastic seismic movements. Displacement, base shear and axial force at various levels of guyed mast are computed and validated. The seismic response of precedent guyed masts isolated with a Friction Pendulum System (FPS) is examined under the same input seismic accelerograms and compared with the procured results.This evolution will concede towards an advanced resilient rational model for simplified seismic analysis of guyed masts.
\end{abstract}

Keywords: Guyed Mast, Dynamic behavior, Seismic analysis, Friction Pendulum System, Finite Element Program

\section{Introduction}

Guyed telecommunication masts are slender structures entailing several sets of laterally supported guy cables anchored to the ground. It has the capacity to withstand its own weight by exhibiting considerable amount of compressive strength, but does not possess enough shear strength to stand unsupported. So pre tensioned guy cables of three numerals at each level spaced at an equal angle of $120^{\circ}$ in vertical plane are attached from the centroid of the mast to an outrigger. It maintains the stay levels upright and prevents the mast from buckling. The mast is subjected to the excitation of ground motions observed from the PEER (Pacific Earthquake Engineering Research) database. Finite element program ABAQUS is used to analyze the terms of structural design which governs to withstand the lateral seismic forces. The optimization of the seismic response may be a complicated venture, since the structural behavior of guyed mast is intricate due to the inherent nonlinearity of the guys.Gregory M. Hensley et al [1]imposed the amplified Northridge and El Centro earthquake on a $120 \mathrm{~m}$ tall guyed mast. The structure considered resembles the mast analyzed by Desai et al [5] and Irvine [6].Responses associated with free vibrations were computed which exhibited periods of slackness and snap loads with an increase in tension. Bending moments, base shears, Horizontal and vertical displacements, vertical forces and tension in guys were computed for the mast. GhodratiAmiri et al. [2]advocated seismicsensitivity indicators in guyed masts for the dynamic analysis due to seismic effects. This incorporates a detailed study on nonlinear earthquake effects on eight guyed telecommunication masts with varying heights. The dynamic component of the axial force in the guyed mast and tension of guy cable coupled with maximum base shear is related by the seismic indicators. S. Ali GhafariOskoeiet al. [3]investigated the numerical simulations from eight existing guyedmasts with varying heights. To replace the nonlinear time variant stiffness of the cable, a mathematical procedure based on the response spectra of guy cables and the frequency of the seismic excitation was developed with an equivalent linear frequency dependent spring mass system. The results of detailed nonlinear finite element analysis and main response indicators of these equivalent models are computed and compared.Matthew Grey [4]analyzed four existing guyed masts with varying heights under various seismic loading conditions using SAP2000. The distribution and magnitudes of forces developed during seismic and wind loads, and the suitability of a response spectrum analysis were observed.

From the literature disquisition, numerical modeling study for four tall guyed masts subjected to seismic excitations are to be carried out. Since guyed masts parade remarkable nonlinearities in geometry, experimental studies of scaleddown models are very complex and of limited usefulness. Using ABAQUS scrutiny, bending moment, base shear and axial force of the mast are enumerated and validated.

\section{Description of Mast and Earthquake Excitation}

A guyed mast is a spatial structure exhibiting response in all three directions. The members fabricating the mast are rolled steel sections and comprehensive three-dimensional guy cables where all members are pin ended and assumed to remain in the linear elastic range of material behavior. Foundations of the mast are assumed perfectly rigid. The base of the mast is modeled to defy the torsional rotation, but free to rotate about the $\mathrm{X}$ and $\mathrm{Y}$ axes. The mast has diverse guy levels with three guys per level and respective sets of guy anchors in each plane.Thegeometry of the masts [4] is epitomized in Table 1. The weight of the masts per unit length is $588 \mathrm{~N} / \mathrm{m}$, its modulus of elasticity and moment of inertia for bending is $209 \mathrm{GPa}$, and 0.0018 $\mathrm{m}^{4}$ respectively.The distribution of mass throughout, in addition to the static load case is important in the determination of the various vibration modes of the mast. As the height of mast increases, considerable member strength is required to support the self-weight and resist lateral loads. So 


\section{International Journal of Science and Research (IJSR) \\ ISSN (Online): 2319-7064 \\ Index Copernicus Value (2013): 6.14 | Impact Factor (2015): 6.391}

guy cables are provided for which the geometry is designed based on the initial pretension force and then defined by ABAQUS. However during analysis, the guy cable stretches to an extent due to self-weight and exhibits increase in sag thus reducing the tension. Besides this loss of tension, the mast undergoes compression under loading and reduces the tension in the guys further. As guy cables with an offset connected to the outer side of the mast with an offset complicated the analysis procedure, they are assumed to be connected from the centroid of the mast to the outrigger. However the additional eccentric moment i.e., P- $\Delta$ effect at stay level connection points will not be considered. Hensely [1] explained that the mast response is more vulnerable to variations in mast stiffness which summit this point.

Table 1: Structural details of mast

\begin{tabular}{|l|c|c|c|c|c|}
\hline Mast & $\begin{array}{c}\text { Height } \\
(\mathrm{m})\end{array}$ & $\begin{array}{c}\text { Outer } \\
\text { Support } \\
\text { radius }(\mathrm{m})\end{array}$ & $\begin{array}{c}\text { No. of } \\
\text { stay } \\
\text { level }\end{array}$ & $\begin{array}{c}\text { No. of } \\
\text { anchor } \\
\text { levels }\end{array}$ & $\begin{array}{c}\text { Average } \\
\text { Mast Mass } \\
(\mathrm{kg} / \mathrm{m})\end{array}$ \\
\hline Mast A & 99.88 & 44.65 & 3 & 1 & 138.55 \\
\hline Mast B & 245.00 & 176.9 & 4 & 2 & 348.92 \\
\hline Mast C & 239.30 & 238.5 & 5 & 3 & 369.15 \\
\hline Mast D & 313.60 & 267.6 & 6 & 2 & 357.85 \\
\hline
\end{tabular}

The foremost reason for the endurance of guyed masts is to support accessories like transmission lines and antennae for telecommunication. So the structures should be analyzed with extra mass loading asthe ancillaries and other components are notmodeled. The percentage mass distribution for all the masts is almost uniform with average values ranging from $60 \mathrm{~kg} / \mathrm{m}$ to $600 \mathrm{~kg} / \mathrm{m}^{4}$. The percentage of the total mass range from $14 \%$ to $28 \%$ and it increases with height of the mast and the number of cables. The percentage of additional load in Mast $\mathrm{A}$ is $37 \%$, whereas Masts B, C and D account 16\%, 20\% and 5\%. The average value represents the lateral stiffness of each guy cable and the initial cable tension varies from $10 \%$ to $15 \%$. The tension in the guy cable is expressed as a percentage of ultimate tensile strength ranging from $8 \%$ to $12 \%$. The diameter of the guy cables are manifested in table 2 . The profile portrait of masts is sketched in figure 1 expressed in meter.

Table 2: Nominal diameter of Guy cables in $\mathrm{mm}$

\begin{tabular}{|c|c|c|c|c|c|c|}
\hline \multirow{3}{*}{ Mast } & \multicolumn{7}{|c|}{ Stay levels } \\
\cline { 2 - 8 } & level & level & level & level & level & level \\
\hline $\mathrm{A}$ & 3 & 2 & 3 & 4 & 5 & 6 \\
\hline $\mathrm{B}$ & 32 & 45 & 45 & 0 & 0 & 0 \\
\hline $\mathrm{C}$ & 40 & 4.5 & 31.8 & 47.6 & 0 & 0 \\
\hline $\mathrm{D}$ & 34.9 & 47.6 & 5.8 & 57.2 & 41.3 & 41.3 \\
\hline
\end{tabular}

The synthesized input accelerograms interact with the base of the mast exhibiting wide range of vibration frequencies. The earthquake accelerograms are made to coincide with the principal direction of the cross section of mast so as to create maximum effects on the mast without any torsional movement. During earthquake, high spectral values were perceived, especially at the accelerograph stations installed in Chavriata station (CHV1), Paliki Peninsula and the data has been observed from PEER database. Spectral acceleration values at CHV1 reached up to $2900 \mathrm{~cm} / \mathrm{s}^{2}$ in the North south components at low periods $\mathrm{T}=0.25 \mathrm{sec}$, while in intermediate periods $\mathrm{T}=0.8 \mathrm{sec}$, The Peak Ground
Acceleration PGA $=0.77 \mathrm{~g}$ at the Chavriata station $(\mathrm{CHV} 1)$ was the greatest value recorded to date in Greece. This stations fall in near field at a distance of about $7 \mathrm{~km}$ from the earthquake epicenter and also within the rupture zone of the earthquake. The chavirata response is particularly high for lower periods and will exhibit significant response from mast A. Accurate modeling of this effect in a time history analysis in ABAQUS accounts for potential geometric nonlinearities.

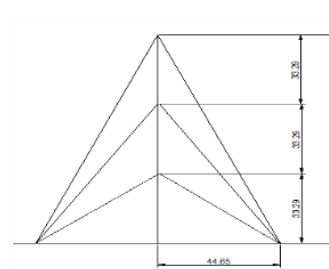

(a)

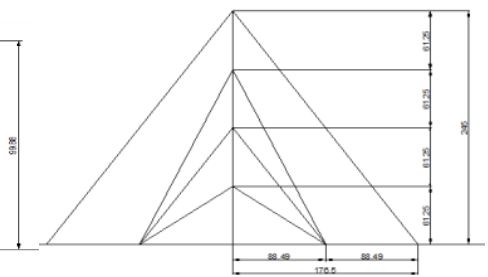

(b)

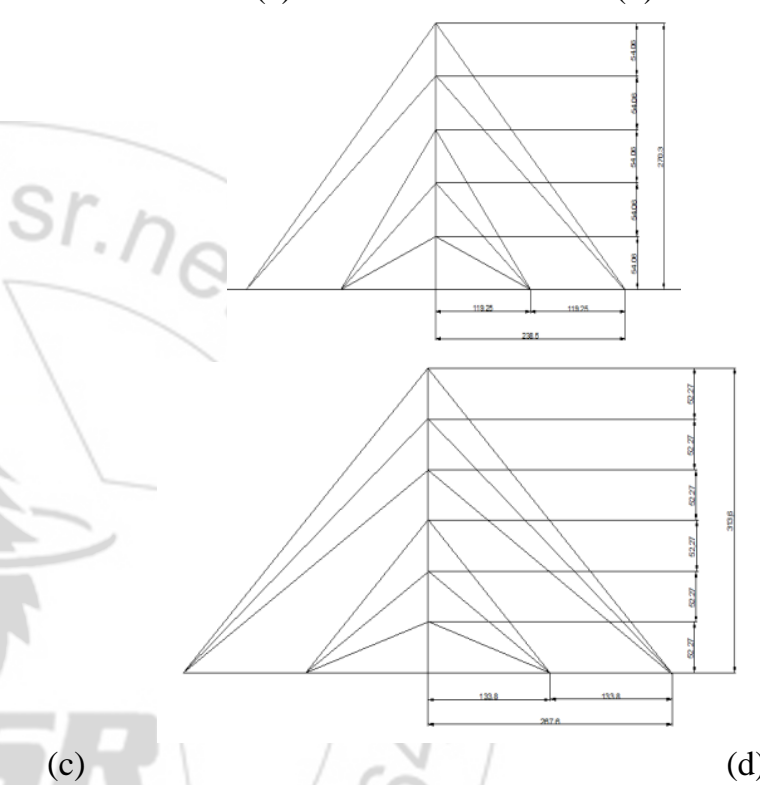

Figure 1:Profile portrait of Guyed Mast (a) Mast A; (b) Mast B; (c) Mast C; (d) Mast D

\subsection{Results of Dynamic Analysis}

Although there are regions of susceptibility, response of the mast was analyzed for drastic seismic accelerograms. When considering the vibration of each span, the restraint of each guy cable support is low. The opposing bending in adjacent spans increases the sagging moment in each span and reduces the hogging moment at the supports. Fundamental periods for the masts in terms of frequency vary from 0.7 to $2.3 \mathrm{~Hz}$, and the lowest lateral modes in the frequency range of 0.3 to $2 \mathrm{~Hz}$. Close investigation exhibited that the overall response was linear, when the peak response occurred at different time steps which have a significant impact on the development of an equivalent static method as depicted in figure 2. As the scale of the input accelerograms increases, the peak base shear also increases. But the isolated peak response decreases with a PGA scale factor of 3.5. Hence, the overall response of the guyed mast acts similar to each of the scale factors with similar oscillation patterns throughout. 


\section{International Journal of Science and Research (IJSR)

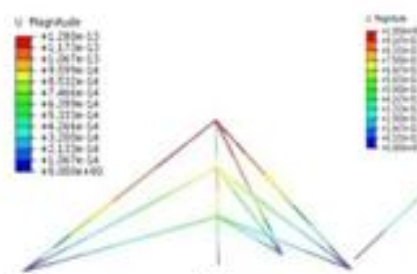

(a)

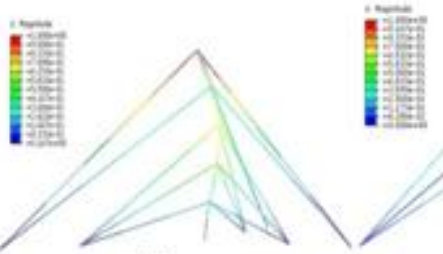

(c)

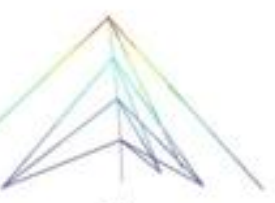

(b)

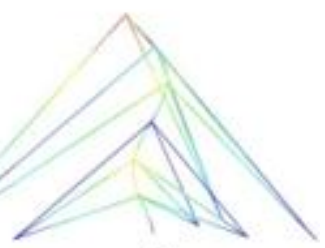

(d)
Figure 2: Dynamic analysis in ABAQUS (a) Mast A; (b) Mast B; (c) Mast C; (d) Mast D

The base shears were obtained by affixing all horizontal support reactions at the supports of mast and guy cables. The masts generally responded significantly to the synthesized accelerograms of CHV1. Mast A exhibits a natural frequency of $2.15 \mathrm{~Hz}$ with increased cable mast interaction. While thenatural frequencies of masts $\mathrm{B}, \mathrm{C}$ and $\mathrm{D}$ are computed to be less than $1 \mathrm{~Hz}$ and their response is complicated. The base shear depicted in Figure 3of guyed mast is calculated about $23 \mathrm{kN}$ for Mast D which is the highest and $14.5 \mathrm{kN}, 9 \mathrm{kN}, 13$ $\mathrm{kNfor}$ Mast A, B and C respectively. The effect of the cables to the total base shear occupies the range of 2 to $4 \%$ of the total weight of mast. The maximum base shear occurs at stay levels and the minimum base shear occurs at mid span between two stay levels. For Mast $D$, the relative contribution of the cables increases with increase in height of the mast.When the vertical component of the earthquake is also considered, the axial force plays a predominant role as these results correspond to the effect of combined vertical and horizontal accelerations. When Peak ground acceleration reaches the peak value, the maximum dynamic component of the axial force occurs at the base of the Mast D. Figure 4 depicts the peak axial force of $200 \mathrm{kN}$ for Mast D and 155 $\mathrm{kN}, 120 \mathrm{kN}, 142 \mathrm{kN}$ for Mast A, B and C respectively. The axial force contribution of the cable to the total dynamic component is in the range of 2 to $4 \%$ of the total weight of the mast.The behavior of the Mast $\mathrm{D}$ contradicts that the mast with low axial modes has lower frequencies of $4 \mathrm{~Hz}$ compared to the other masts.During analysis the masts exhibited horizontal displacements at the base and at the guy levels. The minimum values of displacement occur directly at stay levels and the maximum displacement occurs at mid span between two stay levels.

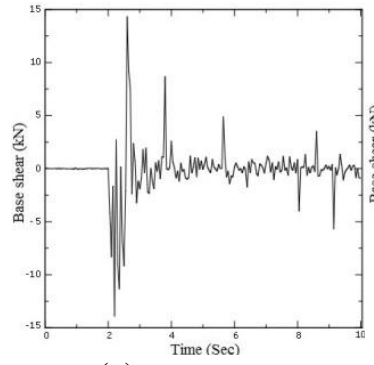

(a)

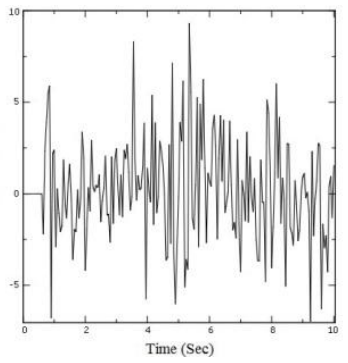

(b)

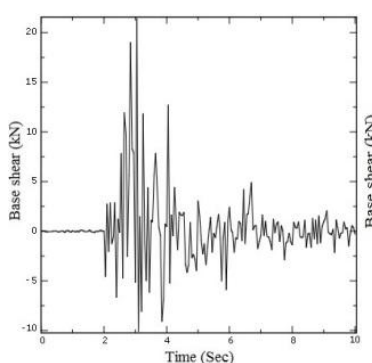

(c)

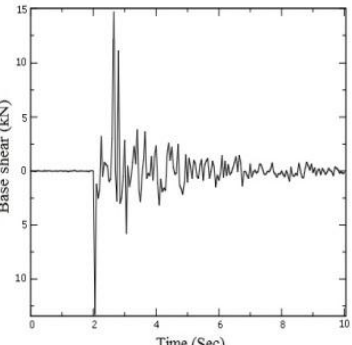

(d)

Figure 3: Base shear (a) Mast A; (b) Mast B; (c) Mast C; (d) Mast D

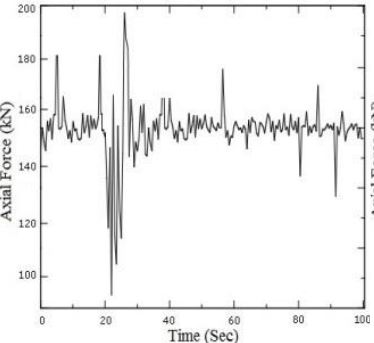

(a)

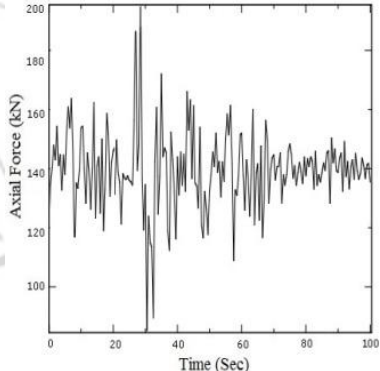

(c)

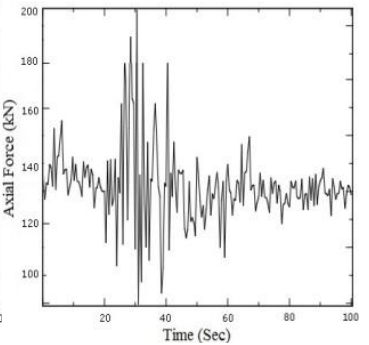

(b)

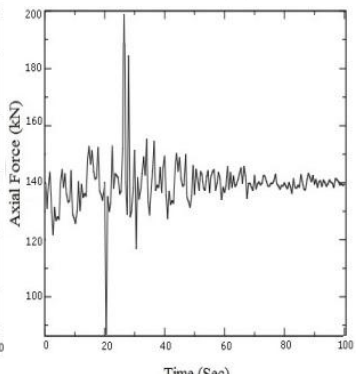

(d)

Figure 4: Axial Force (a) Mast A; (b) Mast B; (c) Mast C; (d) Mast D

The plots of displacements at top represent displacements relative to the ground motion, whereas the plots of displacements at base represent the ground motion, as the relative displacement is zero. However masts B, C and D with reduced support and horizontal stiffness at the cable show considerable bending in the entire span of the mast.Figure 5depicts the displacement at the base of all the masts and time histories of the relative displacements at the top and base of the mast in which the Mast D exhibits peak displacement at the top of about $1.7 \mathrm{~m}$ and $0.6,1,1.2$ for Mast $\mathrm{A}, \mathrm{B}$ and $\mathrm{C}$ respectively.The maximum dynamic component of peak cable tension response of the masts is difficult to characterize. Figure 6 portrays thatMast A, B and $\mathrm{C}$ shows a linear increase to the CHV1 accelerograms with PGA of $1500 \mathrm{~m} / \mathrm{s}^{2}$. Whereas Mast D with slackness guy system exhibits a rise in pretension to $150 \mathrm{kN}$. It is also observed that for all masts the combination of horizontal and vertical accelerograms does not increasethe dynamic cable tensions, compared to the horizontal loading case. 
International Journal of Science and Research (IJSR)

ISSN (Online): 2319-7064

Index Copernicus Value (2013): 6.14 | Impact Factor (2015): 6.391
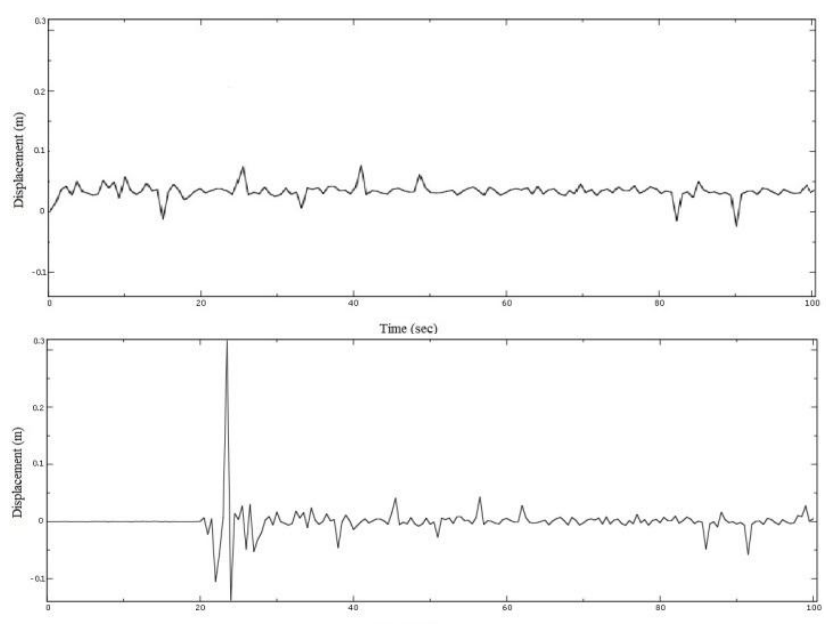

(a)

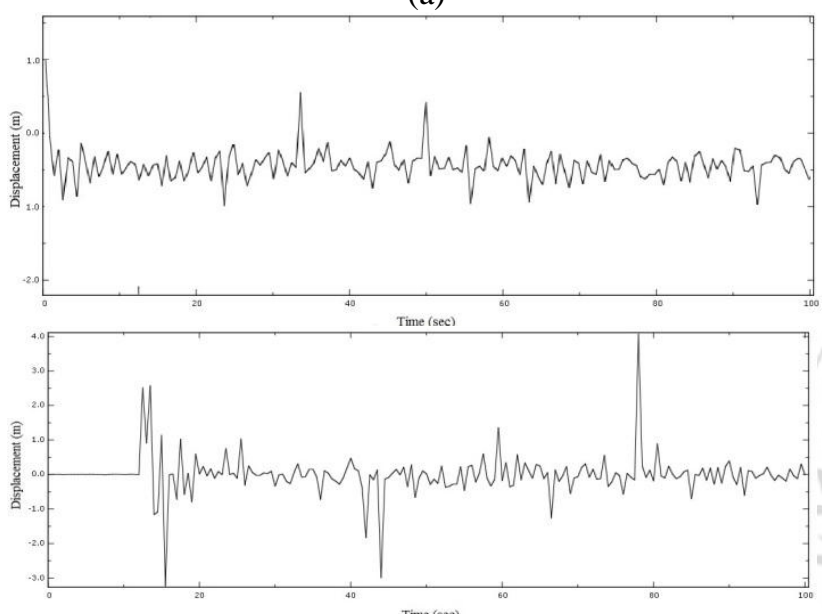

(b)
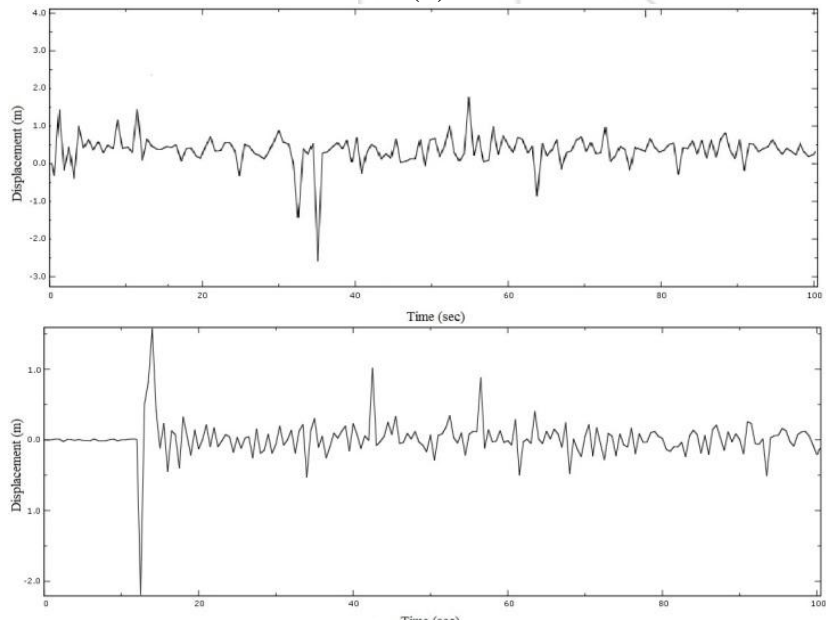

(c)

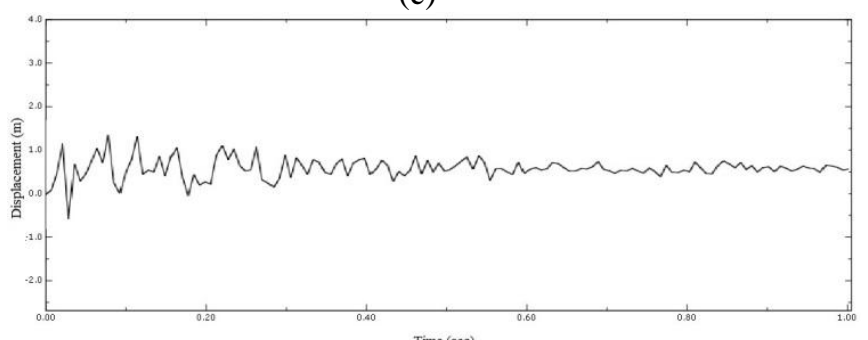

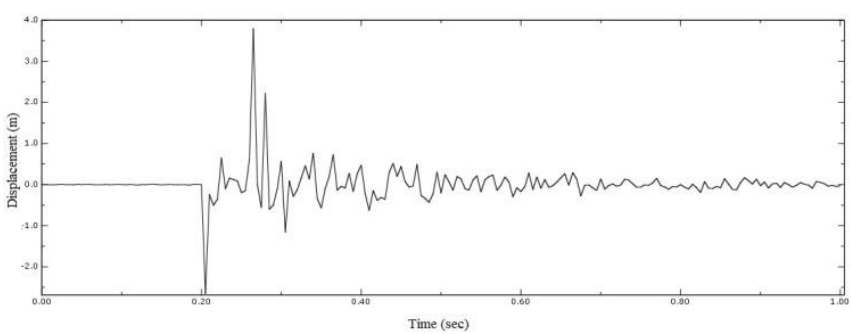

(d)

Figure 5: Displacement at top and base of the mast(a) Mast A; (b) Mast B; (c) Mast C; (d) Mast D

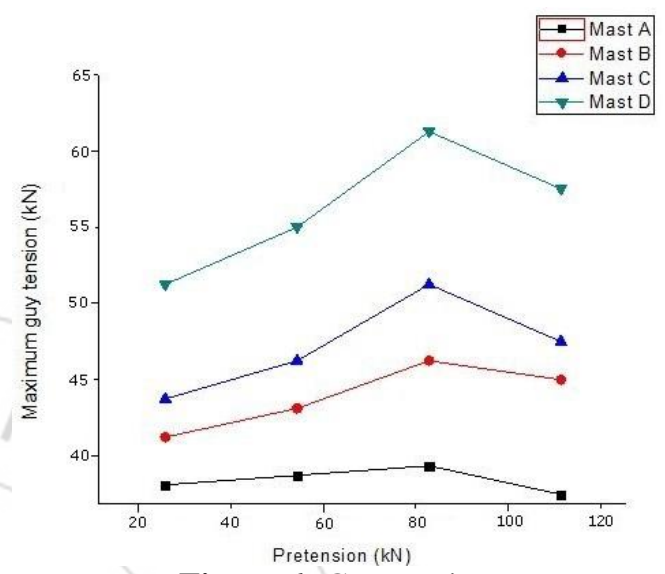

Figure 6: Guy tension

\section{Isolation of Guyed Mast Using FPS}

During the past decade, an amplifying database of strong peak ground acceleration produces devastating displacement to the structures which can be supplemented by dampers. However, additional damping may increase the response of the superstructure, for which base isolation is intended thus defeating many gains. Nonlinear time history analyses of the guyed masts isolated with Friction Pendulum system are performed in ABAQUSto determine the dynamic behavior.For the friction pendulum system isolators depicted in figure 7, the values [8] are given as $T \mathrm{~b}=2.5 \mathrm{~s}$ and $\mu=0.05$ to demonstrate the seismic response. The peak value of the impulsive displacement for FPSis $2.3 \mathrm{~mm}$. A total of 7 isolators are employed, one isolator between the base and foundation of the mast and the others at the anchor points as illustrated in figure 8 . The properties for analysis are assumed as damping ratio is specified as 5\%, frictional coefficients $\mathrm{m}=0.09$, Effective radius of curvature $\mathrm{R}_{\mathrm{eff}}=$ $1.4 \mathrm{~m}$ and displacement capacities $\mathrm{d}=0.40 \mathrm{~m}$. To summate the dead load of the isolator, the acceleration of gravity in the vertical component is included using a ramp function. The first four periods of the isolated guyed masts from the modal analyses are 3.628, 3.010, 2.134 and 1.009. 


\section{International Journal of Science and Research (IJSR) \\ ISSN (Online): 2319-7064}

Index Copernicus Value (2013): 6.14 | Impact Factor (2015): 6.391

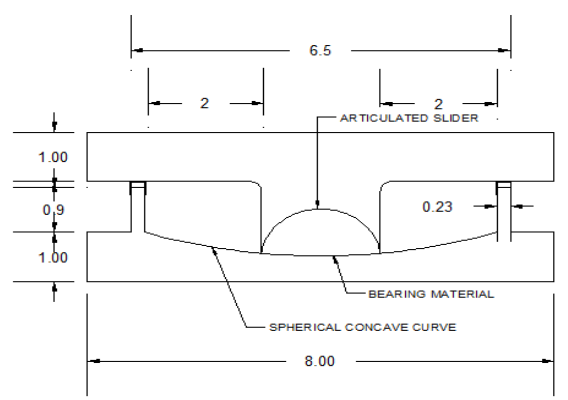

Figure 7: Cross Sectional view of FPS

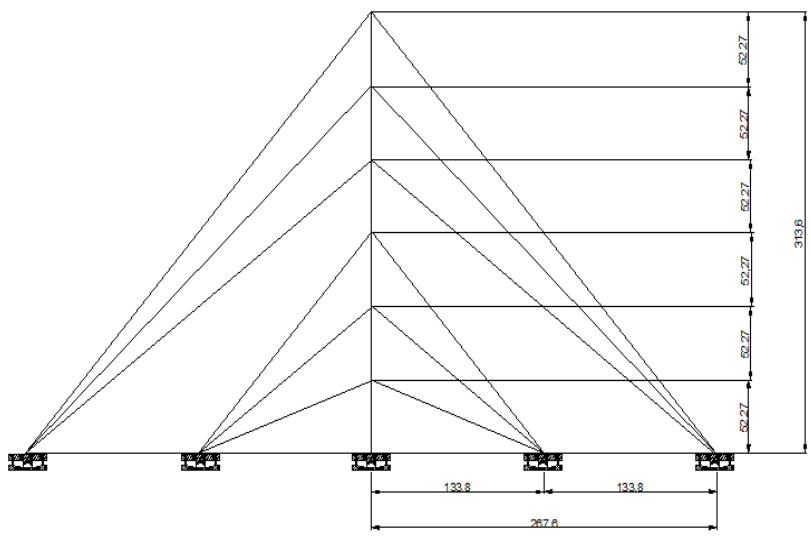

Figure 8: Profile portrait of Mast D isolated with FPS

Isolators drastically decrease the shear response and axial force on the masts during seismic analysis. Similarly maximum mast shear forces obtained from analysis are depicted in figure 9. Decreasing percentage of shear forces on the masts are $87.7 \%, 90.48 \%, 95.44 \%$ and $95.24 \%$. And also the axial force responses corresponding to the figure 10 shows a drastic decrease in the value of axial force and the peak value recorded for mast $\mathrm{D}$ is $147 \mathrm{kN}$ and that of masts $\mathrm{A}, \mathrm{C}$ and $\mathrm{D}$ also decreases compared to the previous results.

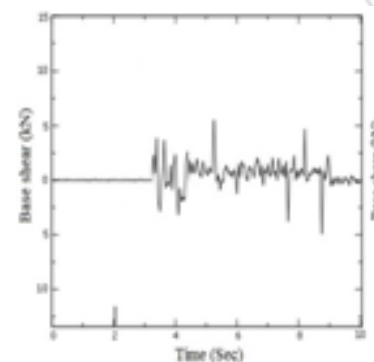

(a)

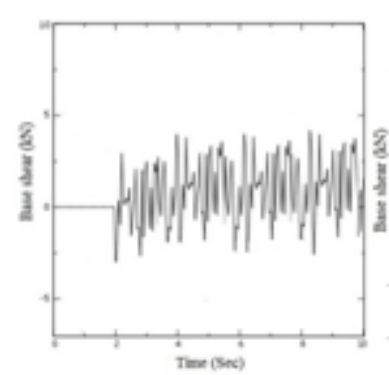

(c)

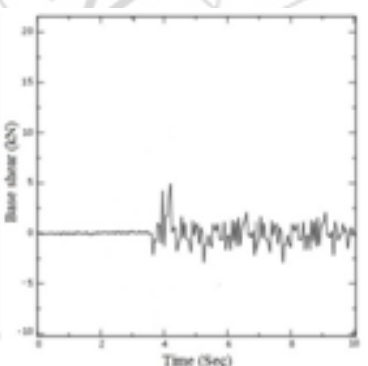

(b)

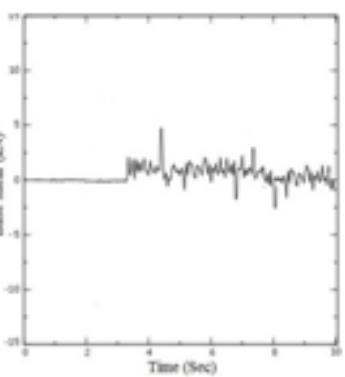

(d)
Figure 9: Base shear after isolation(a) Mast A; (b) Mast B; (c) Mast C; (d) Mast D

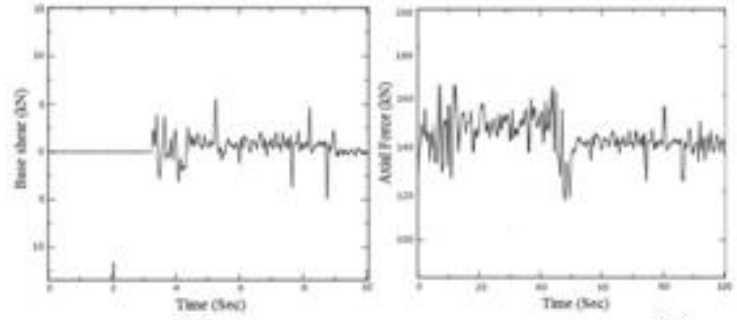

(a)

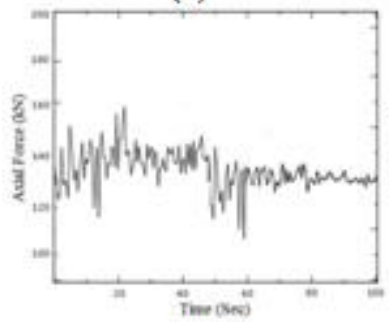

(c)

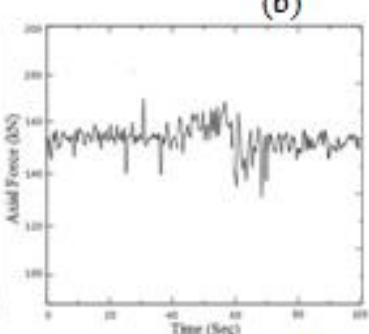

(d)
Figure 10: Axial force after isolation (a) Mast A; (b) Mast B; (c) Mast C; (d) Mast D

Decreasing percentage of vertical displacements for the masts earthquake ground motions are $66.78 \%, 71.22 \%$, $75.32 \%$ and $81.14 \%$. Figure 11 portrays the displacement deliberated.It reveals that the displacement at the top of the mast for both isolated and non-isolated are similar, but the change in frequency of displacement is higher for nonisolated masts. Onthe contrary, displacement at the base forisolatedand non-isolated masts varies intermsofvalueandfrequency of displacement. Figure 12 depicts the peak cable tension response of the masts which exhibits a decline in pretension.

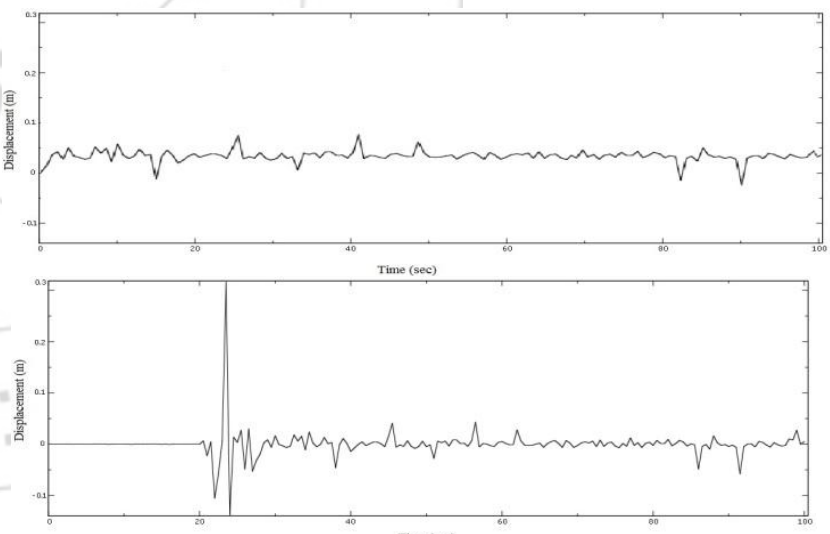

(a)

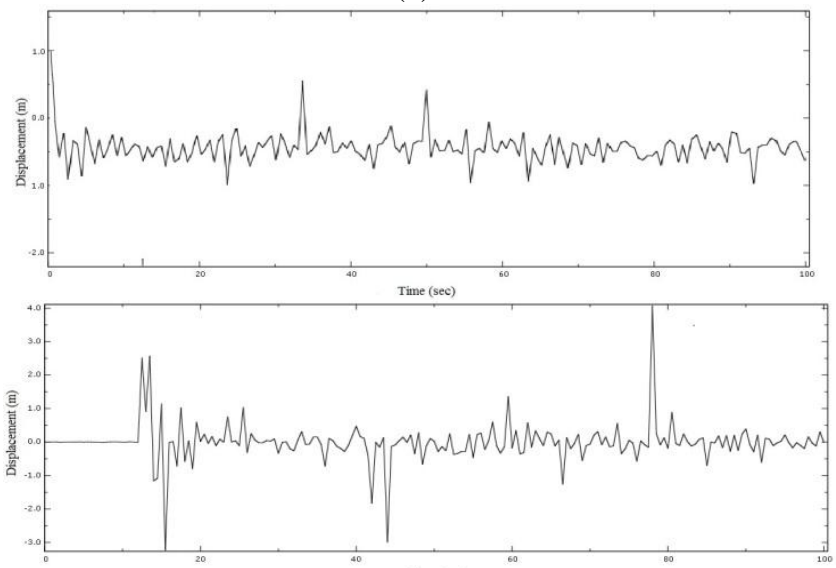

(b) 


\section{International Journal of Science and Research (IJSR) \\ ISSN (Online): 2319-7064}

Index Copernicus Value (2013): 6.14 | Impact Factor (2015): 6.391

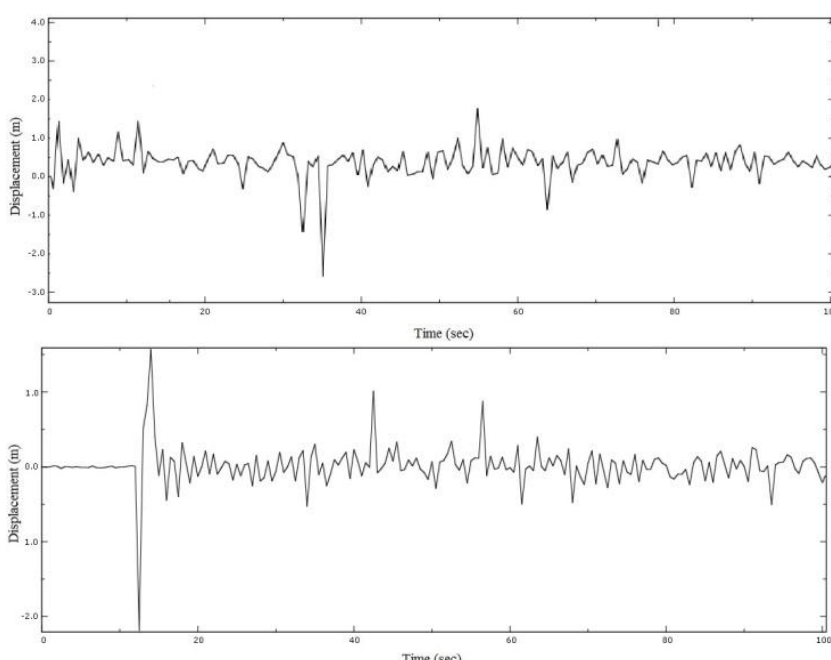

(c)
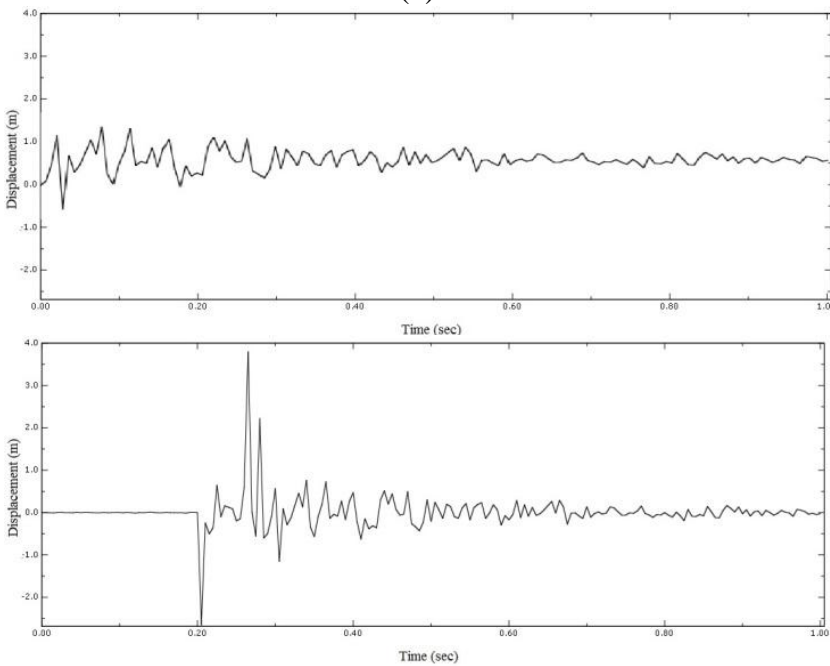

(d)

Figure 11: Displacement at top and base of the mast after isolation(a) Mast A; (b) Mast B; (c) Mast C; (d) Mast D

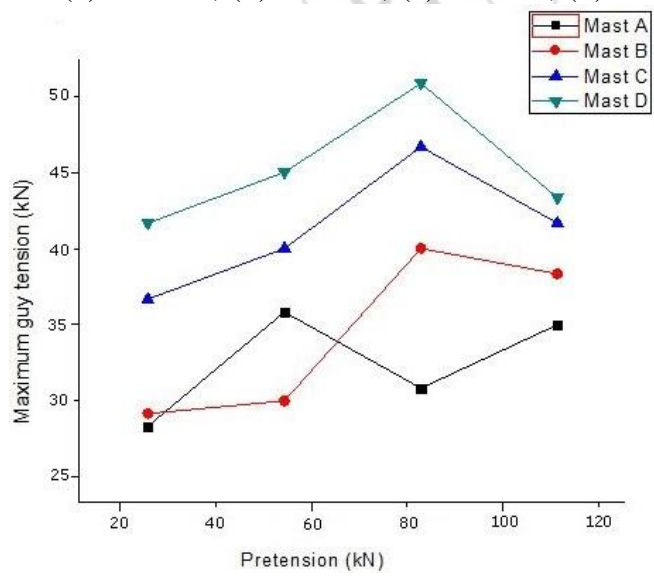

Figure 12: Guy tension after Isolation

\section{Summary and Conclusion}

It is of paramount importance to evoke the important parameters of the study which directly influence the numerical results. The level of seismicity is constant with PGA $752 \mathrm{~cm} / \mathrm{s}^{2}$ and PGV $62 \mathrm{~cm} / \mathrm{s}$. The realistic vertical accelerograms typically exhibit higher frequency than horizontal ground motions. The results were used to assess similarities in behavior between the masts and identify the factors that could be used to characterize their response and show the accuracy and precision of the finite element analysis.

- Free vibrations examined exhibited that themaximum horizontal displacement occurred in the strong direction of the earthquake corresponding to the top of the mast.The shape of the mast changed during motion and dominates the vibration modes associated with the snap loads in the guy cables.

- Installation of Friction pendulum system controls the base shear, axial force and pretension of guys without any alteration in impulsive displacement.The optimum time period of the isolator for the guyed mast is found in the vicinity of $1.5 \mathrm{~s}$ thus attaining a minimal value of displacement and internal reactions.

- The maximum base shear was reduced to $80 \%$ andthe maximum axial force was reduced to $85 \%$ for MastD.

- When vertical seismic movement is considered, cable tension is calculated around $10 \%$ of ultimate tensile strength and hence the maximum dynamic component at the base of the mast due to horizontal and vertical ground motion is about $90 \%$ of the total weight of the mast.

- As the pre-tension of the guy cables were increased, maximum horizontal displacements of the mast were reduced thus increasing the maximum vertical displacements.Different lateral stiffness is observed between adjacent guy clusters due to the discontinuities in behavior of isolated guyed masts.

- When vertical accelerations are contemplated, cable mast dynamic interaction occurs which are difficult to predict and detailed analysis is recommended for very tall mastswith relatively slack guy clusters.

- All the Guyed masts analyzed acquitted within serviceability Limits.

\section{References}

[1] Hensley GM, Plaut RH, "Three-dimensional analysis of the seismic response of guyed masts", Engineering Structures 29 (2007), page 2254-2261.

[2] GhodratiAmiri G, "Seismic sensitivity indicators for tall guyed telecommunication towers", Computational Structures 80 (2002), page 349-364.

[3] S. Ali GhafariOskoei, Ghyslaine McClure, "A novel approach to evaluate the equivalent dynamic stiffness of guy clusters in telecommunication masts underground excitation", Engineering Structures 33 (2011), page 1764-1772.

[4] Matthew Grey, "Finite Element Seismic Analysis of Guyed Masts"Research at the University of Oxford (2006)

[5] Desai YM, Punde S, "Simple model for dynamic analysis of cable supported Structures", Engineering Structures 23 (2001), page 271-279.

[6] Irvine HM,“Cable structures", Cambridge (MA): The MIT Press(1981).

[7] Madugula MKS, "Dynamic response of lattice towers and guyed masts", American society of civil engineers task committee on the dynamic response of lattice towers (2002). 


\section{International Journal of Science and Research (IJSR) \\ ISSN (Online): 2319-7064}

Index Copernicus Value (2013): 6.14 | Impact Factor (2015): 6.391

[8] BarbarosAtmaca, MuhammetYurdakul, SevketAtes,"Nonlinear dynamic analysis of base isolated cable-stayed bridge under earthquake excitations", $\quad$ Soil DynamicsandEarthquakeEngineering66(2014), page 314-318.

[9] McClure G, Lin N, “Transient response of guyed telecommunication towers subjected to cable iceshedding",Proceedings of the IASS-ASCE international symposium (1994), page 801-809.

[10] Xu X, He Z, Zhi-cheng Z, "Nonlinear dynamic response ofstay cables under axial harmonic excitation", Journal of ZhejiangUniversity 9 (2008), page 1193-1200.

[11] Bao W. L, Zhang Y, "Non-linear analysis and design of a guyed mast: comparison of two design proposals", Proceedings ofthe International Conference on Structures and Building Materials (2011), page 165168.

[12] Marcel I, Jose G, Pedro C, "Structural Analysis of GuyedSteel Telecommunication Towers for Radio Antennas", Journal ofthe Brazil Society of Mechanical Science \& Engineering 16 (2007), page 185.

[13] Ma Xing, "Research on vibration theory and effect coefficient of guyed mast under wind load", Doctoral Dissertation (1999), Tongji University, Shanghai.

[14] Peil U, Nolle H (1992), “Guyed masts under wind load", Journal of Wind Engineering and Aerodynamics 41 (1992), page 2129-2140.

[15] Harikrishna P, Shanmugasundaram J, Gomathinayagam S,Lakshmanan N, "Analytical and experimental studies on thegust response of a $52 \mathrm{~m}$ tall steel lattice tower under wind loading",Computational Structures 70 (1999), page 149-160.

[16] Davenport AG, Spalding BF (1992), "Dynamic gust response factorsfor guyed tower", Journal of Wind Engineering and Aerodynamics 43 (1992), page 22372248 .

\section{Author Profile}

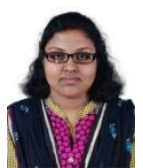

Adlin Nelofer J, pursuing Post Graduate in Structural Engineering, Department of Civil Engineering, Mepco Schlenk Engineering College, Sivakasi. Her area of interest incorporates Seismic Analysis of Structures and Design of Steel Structures. She has presented 2 International and 1 National conference.

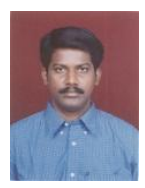

MR. N. Saravana Kumar, an Assistant Professor, Department of Civil Engineering, Mepco Schlenk Engineering College, Sivakasi. His area of specialization encrusts Design of RC Structures, Structural Analysis and Design. He has published 4papers in International Journal and partook 12 International and 21 National Conferences. He has organized an International, 4 National and 14 State level courses and participated in 5 National and 8 State level courses. 